\title{
Allogeneic adipose-derived stem cell transplantation on knee osteoarthritis rats and its effect on MMP-13 and DDR2
}

\author{
JIANRUI LI ${ }^{1}$, XIAOBO ZHU ${ }^{2}$, QIN SHAO $^{1}$, FEINI XU ${ }^{3}$ and GUIXIN SUN ${ }^{1}$ \\ ${ }^{1}$ Department of Traumatology, Shanghai East Hospital Tongji University, Shanghai 200123; \\ ${ }^{2}$ Department of Preventive Medicine, Army Medical University, Chongqing 400038; \\ ${ }^{3}$ Department of Dermatology, Chongqing Medical University, Chongqing 400016, P.R. China
}

Received November 9, 2018; Accepted March 12, 2019

DOI: 10.3892/etm.2019.7554

\begin{abstract}
This study investigated the efficacy of transplantation of allogeneic adipose-derived stem cells (ADMSCs) in rats with knee osteoarthritis (KOA) and the effect on the expression of matrix metalloproteinase 13 (MMP-13) and discoid domain receptor 2 (DDR2). In total, sixty rats were randomly selected. Eleven rats were selected as the blank group. Forty-four rat KOA models were established, and the remaining 5 rats were used for stem cell extraction. The rats were randomly divided into two groups, and the transplantation group was treated with ADMSCs transplantation. The KOA group was intragastrically administered with saline. The expressions of MMP-13 mRNA and DDR2 in rats were detected by RT-qPCR and immunohistochemistry. Correlation analysis was performed in MMP-13 mRNA and DDR2 expression levels in the KOA rats. After treatment, the indexes of Lequesne MG knee joints, MMP-13 mRNA and DDR2 in the transplanted rats were significantly lower than those in the KOA group $(\mathrm{P}<0.05)$. In the KOA rats, MMP-13 mRNA and DDR2 was positively correlated $(r=0.830, P<0.001)$. Therefore, the transplantation of ADMSCs has a significant effect on the KOA rats, which can effectively improve the knee joint function of KOA rats and reduce the expression of MMP-13 mRNA and DDR2 in rats, and it is worthy of clinical promotion.
\end{abstract}

\section{Introduction}

Knee osteoarthritis (KOA) is a degenerative disease that occurs in the elderly and has a high incidence. It is one of the main causes of activity disorder and joint pain in the elderly, threatening life and health as well as the quality of life for the elderly $(1,2)$. At present, there is no relevant research to elaborate

Correspondence to: Dr Guixin Sun, Department of Traumatology, Shanghai East Hospital Tongji University, 1800 Yuntai Road, Shanghai 200123, P.R. China

E-mail: gby25t@163.com; dfyysgx2014@163.com

Key words: allogeneic adipose stem cells, knee osteoarthritis, animal model, matrix metalloproteinase 13, Discoid domain receptor 2 the pathogenesis of KOA. Some studies have suggested that one of the important mechanisms of KOA pathogenesis is apoptosis of articular chondrocytes (3), or the result of losing balance in synthesis and catabolism of articular cartilage (4).

Matrix metalloproteinase-13 (MMP-13), a key enzyme that mediates the degradation of extracellular matrix, can degrade $90 \%$ of type II collagen in the extracellular matrix (5). Thus, MMP-13 expression is closely related to the onset of KOA. Discoid domain receptor 2 (DDR2) is a receptor-type tyrosine kinase with ligands called fibrillar collagen, which are widely distributed (6). Studies have shown that type II collagen can activate DDR2, and this powerful activation can promote the continuous activation of DDR2, which can cause the synovial membrane to continuously secrete MMP-1 and MMP-2, which can cause severe damage to cartilage, thereby causing bone and joint lesion $(7,8)$. Adipose-derived stem cells are a kind of special stem cells with strong multi-directional differentiation ability and exist in adipose tissue (9). Compared with bone marrow mesenchymal stem cells, adipose stem cells not only have less difficulty in obtaining, but have a high acquisition rate, which can also differentiate into osteoblasts, chondrocytes and other cells after induction, with a high application advantage $(10,11)$.

However, the current research on the treatment of KOA with adipose-derived stem cell transplantation is rare. Therefore, the effects of allogeneic adipose-derived stem cell (ADMSCs) transplantation on the KOA rats and the effects on MMP-3 and DDR2 were investigated, in order to find a better treatment for KOA patients.

\section{Materials and methods}

Experimental animals and materials. Sixty healthy female SD rats aged 8 weeks old and weighing $171.61 \pm 7.52 \mathrm{~g}$ were selected. All rats were purchased from Shanghai Slack Laboratory Animals Co., Ltd. [(Shanghai, China), production license SCXK (Shanghai) 2012-0002], The rats were maintained in plastic boxes with solid padding at a constant temperature of $22^{\circ} \mathrm{C}$, relative humidity (50-65\%), in a 12:12-h light/dark cycle, and were allowed free access to food and water. The operation of the modeling process on rats was in accordance with the standards of the Experimental Animal Ethics Committee of Shanghai East Hospital Tongji University (Shanghai, 
Table I. Related primer sequences.

\begin{tabular}{lll}
\hline Factors & \multicolumn{1}{c}{ Forward primer sequences } & \multicolumn{1}{c}{ Reverse primer sequences } \\
\hline MMP-13 & 5'-TGACTATGCGTGGCTGGA-3' & 5'-GGGAAGGGGCTAATGAACA-3' \\
$\beta$-actin & 5'-CACACTGTGCCCATCTACGA-3' & 5'-CTCAGTGAGGATCTTCATGAGGTAGT-3'
\end{tabular}

MMP-13, matrix metalloproteinase 13.

China). Type II collagenase was purchased from Sigma; Merck KGaA (Darmstadt, Germany); rabbit anti-mouse DDR2 polyclonal antibody was purchased from ImmunoWay Biotechnology Company (Plano, TX, USA); TRIzol reagent was purchased from Invitrogen; Thermo Fisher Scientific, Inc. (Waltham, MA, USA); PCR fluorescence quantitative kit and reverse transcription kit were purchased from Dalian Takara Biotechnology Co., Ltd. (Dalian, China).

Modeling. Eleven rats were randomly selected as the blank group and continued to be kept routinely without any intervention. The rat KOA model was established by collagenase injection $(12,13)$. The model was established by first injecting 49 rats with $360 \mathrm{mg} / \mathrm{kg}$ chloral hydrate with a concentration of $3 \mathrm{mg} / \mathrm{kg}$, wherein 5 rats were used for adipose stem cell extraction and continued conventional feeding. Then, the knee joint of the remaining 44 rats was subjected to knee puncture, and $50 \mu \mathrm{l}$ of the type II collagenase solution at a concentration of $0.4 \mathrm{mg} / \mathrm{l}$ was injected into the joint cavity, and the operation was strictly performed aseptically. On the fourth day, the above process was repeated. After 6 weeks of feeding, 4 rats were randomly selected for cervical dislocation and dissection of the knee joint. If the surface of the articular cartilage of the dissected rat was thinned and the chondrocytes were reduced, fine fractures of the trabeculae of the subchondral bone were observed under a microscope (purchased from Beijing Century Scientific Instrument Co., Ltd., Beijing, China), as well as visible synovial hyperplasia and a large number of lymphocytic infiltrations around the synovial membrane, successful modeling was indicated. After modeling, the remaining 40 rats were randomly divided into two groups, 20 in each group. One group was treated with transplantation of ADMSCs, and the KOA group was treated with normal saline $2 \mathrm{ml} /$ day. MMP-13 and DDR2 were detected in the knee joint tissues of the two groups of rats after 6 weeks of intervention.

Isolation and culture of adipose stem cells. After anesthetizing 5 rats, a part of the subcutaneous adipose tissue was taken out from the groin of the rat and placed in a petri dish, and connective tissue and large blood vessels in the tissue were excised with ophthalmic scissors and the tissue was washed with PBS to a bloodless color. After washing, the tissue was cut and placed in a centrifuge tube; $0.1 \%$ type I collagenase was added to the centrifuge tube and mixed uniformly, and then subjected to water bath digestion at $37^{\circ} \mathrm{C}$. After digestion, centrifuged at $400 \mathrm{x} \mathrm{g}$ for $5 \mathrm{~min}$ at $4^{\circ} \mathrm{C}$, the cells were then resuspended in DMEM complete medium containing 10\% FBS. Then the cells were inoculated in culture flasks, the cell density was adjusted to $5 \times 4^{10} / \mathrm{cm}^{2}$ and culture was continued in a $37^{\circ} \mathrm{C}, 5 \% \mathrm{CO}_{2}$ incubator. When the cells were adherently grown to $80 \%$, the cells were harvested for subsequent stem cell transplantation.

$R T$-qPCR detection of MMP-13 mRNA before and after treatment in the two groups of rats. Venous blood $(2 \mathrm{ml})$ was taken from the rats before and after treatment, and total MMP-13 mRNA in the blood was extracted by adding TRIzol reagent. The concentration and quality of total RNA were detected by ultraviolet spectrophotometer (purchased from ShanghaiMetash Instruments Co., Ltd., Shanghai, China). Total RNA $(2 \mu \mathrm{l})$ was taken and cDNA was synthesized in strict accordance with the instructions of the reverse transcription kit. The synthesized cDNA $(2 \mu 1)$ was subjected to SYBR-Green PCR kit (Beyotime, Shanghai, China), and the reaction conditions of MMP- 13 were: $95^{\circ} \mathrm{C}$ for $4 \mathrm{~min}$, then $95^{\circ} \mathrm{C}$ for $45 \mathrm{sec}, 60^{\circ} \mathrm{C}$ for $30 \mathrm{sec}, 72^{\circ} \mathrm{C}$ for $30 \mathrm{sec}$, and 40 cycles. The expression level of MMP-13 mRNA was detected by using $\beta$-actin as an internal reference substance. The primer sequences are shown in Table I. The relative expression amount was expressed by the $2^{-\mathrm{ACq}}$ method (14), and the experiment was repeated 3 times.

Detection of DDR2 expression by immunohistochemistry. The rats were sacrificed and the knee joint tissue samples were taken. The samples were fixed in $4 \%$ paraformaldehyde buffer for $24 \mathrm{~h}$ at $4^{\circ} \mathrm{C}$, and made paraffin blocks after taken out, then embedded in sections with a thickness of $3 \mu \mathrm{m}$, and then blocked with $5 \%$ milk at room temperature for $1.5 \mathrm{~h}$. A total of $50 \mu \mathrm{l}$ of primary anti-DDR2 monoclonal antibody (1:500; cat. no. k1974Hu21; Shanghai Kanglang Biotechnology Co., Ltd., Shanghai, China) was added dropwise, and the mixture was allowed to stand overnight at $4^{\circ} \mathrm{C}$. Then, the sample was rinsed with PBS 3 times for 5 min each time. A total of $50 \mu 1$ of secondary rabbit anti-mouse monoclonal antibody (1:500; cat. no. PAB9358; Shanghai Qunji Biotech Co., Ltd., Shanghai, China) was added, and let stand in a $37^{\circ} \mathrm{C}$ incubator for $20 \mathrm{~min}$, then rinsed with PBS 3 times, then streptavidin-peroxidation enzyme was added and further allowed to stand at $37^{\circ} \mathrm{C}$ for 20 min, rinsed with PBS 3 times, and then added with DAB for color development (20:1:1). When microscopic observation showed appropriate staining degree, the sample was rinsed with tap water for 15-20 min to terminate the reaction, followed by hematoxylin repeated dyeing for 2-3 min, rinsed again with tap water for 15-20 min. Finally, conventional dehydration and sealing were performed.

The primary antibody was replaced with PBS as a negative control. When brown or yellow-brown particles appeared in the cytoplasm, DDR2 was positively expressed, and 10 fields were randomly selected for positive cell count. 
Table II. Evaluation of Lequesne MG knee joint before treatment in the three groups of rats.

\begin{tabular}{|c|c|c|c|c|c|}
\hline Indexes & $\begin{array}{l}\text { Transplantation group } \\
\qquad(\mathrm{n}=20)\end{array}$ & $\begin{array}{l}\text { KOA group } \\
\quad(n=20)\end{array}$ & $\begin{array}{l}\text { Blank group } \\
\quad(n=11)\end{array}$ & F value & P-value \\
\hline Pain stimulation & $3.71 \pm 0.25^{\mathrm{a}}$ & $3.69 \pm 0.23^{\mathrm{a}}$ & $1.21 \pm 0.13$ & 543.6 & $<0.001$ \\
\hline Gait & $3.81 \pm 0.18^{\mathrm{a}}$ & $3.75 \pm 0.21^{\mathrm{a}}$ & $1.07 \pm 0.05$ & $1,029.0$ & $<0.001$ \\
\hline Joint swelling & $2.95 \pm 0.23^{\mathrm{a}}$ & $2.93 \pm 0.22^{\mathrm{a}}$ & $1.08 \pm 0.04$ & 369.2 & $<0.001$ \\
\hline Joint activity & $3.67 \pm 0.19^{\mathrm{a}}$ & $3.69 \pm 0.18^{a}$ & $1.12 \pm 0.09$ & 981.6 & $<0.001$ \\
\hline
\end{tabular}

${ }^{a} \mathrm{P}<0.05$, compared with the blank group. KOA, knee osteoarthritis.

Table III. Evaluation of Lequesne MG knee joint after treatment in the three groups of rats.

\begin{tabular}{|c|c|c|c|c|c|}
\hline Indexes & $\begin{array}{l}\text { Transplantation group } \\
\qquad(\mathrm{n}=20)\end{array}$ & $\begin{array}{l}\text { KOA group } \\
\quad(n=20)\end{array}$ & $\begin{array}{l}\text { Blank group } \\
\quad(n=11)\end{array}$ & F value & P-value \\
\hline Pain stimulation & $1.14 \pm 0.15^{\mathrm{a}}$ & $3.65 \pm 0.11$ & $1.11 \pm 0.10^{\mathrm{a}}$ & 891 & $<0.001$ \\
\hline Gait & $1.05 \pm 0.04^{\mathrm{a}}$ & $3.69 \pm 0.19$ & $1.07 \pm 0.06^{\mathrm{a}}$ & $2,689.0$ & $<0.001$ \\
\hline Joint swelling & $1.08 \pm 0.03^{\mathrm{a}}$ & $3.01 \pm 0.25$ & $1.03 \pm 0.02^{\mathrm{a}}$ & 916.2 & $<0.001$ \\
\hline Joint activity & $1.12 \pm 0.09^{\mathrm{a}}$ & $3.71 \pm 0.14$ & $1.09 \pm 0.06^{\mathrm{a}}$ & 3,510 & $<0.001$ \\
\hline
\end{tabular}

${ }^{a} \mathrm{P}<0.05$, compared with the KOA group. KOA, knee osteoarthritis.

Observation indicators. i) Three groups of rats were evaluated for Lequesne MG knee joint evaluation level before intervention treatment and 6 weeks after intervention treatment (15), including pain stimulation response, gait response, joint swelling and joint activity, each indicator was divided into four grades, based on previous reports. ii) The expression of MMP-13 mRNA was detected by RT-qPCR before and after intervention in the three groups of rats. iii) The expression of DDR2 was detected by immunohistochemistry before and after intervention in the three groups of rats. iv) Correlation analysis was performed on the expression of MMP-13 and DDR2 in KOA rats.

Statistical analysis. In this study, the SPSS 18.0 software package [Bo Yi (Beijing) Information Technology Co., Ltd., Beijing, China] was used for statistical analysis of the experimental data. The measurement data were expressed using mean \pm standard deviation. The two groups were compared by t-test. Multiple groups were compared using analysis of variance. LSD/t test was used for post hoc comparison. Paired t-test was used for comparison before and after treatment within the group. Pearson's correlation analysis was used for correlation. The experimental pictures were drawn using GraphPad Prism 6 software (Emerald Biotech Co,. Ltd., Hangzhou, China). $\mathrm{P}<0.05$ for the difference was statistically significant.

\section{Results}

Behavioral observation results of the three groups of rats. The Lequesne MG knee joint evaluation indexes of the transplantation and KOA groups were significantly higher than those of the blank group, and the difference was statistically significant $(\mathrm{P}<0.05)$, but there were no significant differences in the indexes of the Lequesne MG knee joint evaluation between the transplantation and KOA groups $(\mathrm{P}>0.05)$. After the treatment, the indexes of Lequesne MG knee joints in the transplantation group were lower than those in the KOA group, and the difference was statistically significant $(\mathrm{P}<0.05)$. There were no significant differences in the indexes of the rats in comparison to the blank group (P>0.05) (Tables II and III).

MMP-13 mRNA expression levels before and after treatment in the three groups of rats. There was no significant difference in the expression of MMP-13 mRNA between the transplanted and KOA rats before treatment $(\mathrm{P}>0.05)$, but they were significantly higher than those in the blank group, and the difference was statistically significant $(\mathrm{P}<0.05)$; MMP-13 mRNA expression in the transplantation group was significantly lower than that in the KOA group, and the difference was statistically significant $(\mathrm{P}<0.05)$. Although the expression level of MMP-13 mRNA in the transplantation group after treatment was still higher than that of the blank group, there was no significant difference $(\mathrm{P}>0.05)$ (Table IV).

DDR2 expression levels before and after treatment in the three groups of rats. There was no significant difference in the expression of DDR2 between the transplanted and KOA rats before treatment $(\mathrm{P}>0.05)$, but they were significantly higher than those in the blank group, and the difference was statistically significant $(\mathrm{P}<0.05)$; DDR2 positive expression in the transplantation group was significantly lower than that in the KOA group after treatment, and the difference was statistically 
Table IV. MMP-13 mRNA expression levels before and after treatment in the three groups of rats.

\begin{tabular}{lcccc}
\hline Time & $\begin{array}{c}\text { Transplantation group } \\
(\mathrm{n}=20)\end{array}$ & $\begin{array}{c}\text { KOA group } \\
(\mathrm{n}=20)\end{array}$ & $\begin{array}{c}\text { Blank group } \\
(\mathrm{n}=11)\end{array}$ & F value \\
\hline Before treatment & $2.27 \pm 0.58$ & $2.19 \pm 0.51$ & $1.02 \pm 0.22$ & 25.78 \\
After treatment & $1.13 \pm 0.26$ & $2.38 \pm 0.49$ & $1.04 \pm 0.24$ & 74.87 \\
t value & 8.021 & 1.201 & 0.204 & - \\
P-value & $<0.001$ & 0.237 & 0.841 & - \\
\hline
\end{tabular}

MMP-13, matrix metalloproteinase 13; KOA, knee osteoarthritis.

Table V. DDR2 positive expression levels before and after treatment in the three groups of rats (\%).

\begin{tabular}{lcccc}
\hline Time & $\begin{array}{c}\text { Transplantation group } \\
(\mathrm{n}=20)\end{array}$ & $\begin{array}{c}\text { KOA group } \\
(\mathrm{n}=20)\end{array}$ & $\begin{array}{c}\text { Blank group } \\
(\mathrm{n}=11)\end{array}$ & F value \\
\hline Before treatment & $28.61 \pm 3.66$ & $28.59 \pm 3.57$ & $18.21 \pm 2.35$ & 40.50 \\
After treatment & $18.72 \pm 2.51$ & $28.21 \pm 3.52$ & $17.92 \pm 2.29$ & 68.65 \\
t value & 9.966 & 0.339 & 0.293 & $<0.001$ \\
P-value & $<0.001$ & 0.737 & 0.772 & - \\
\hline
\end{tabular}

DDR2, discoid domain receptor 2. KOA, knee osteoarthritis.

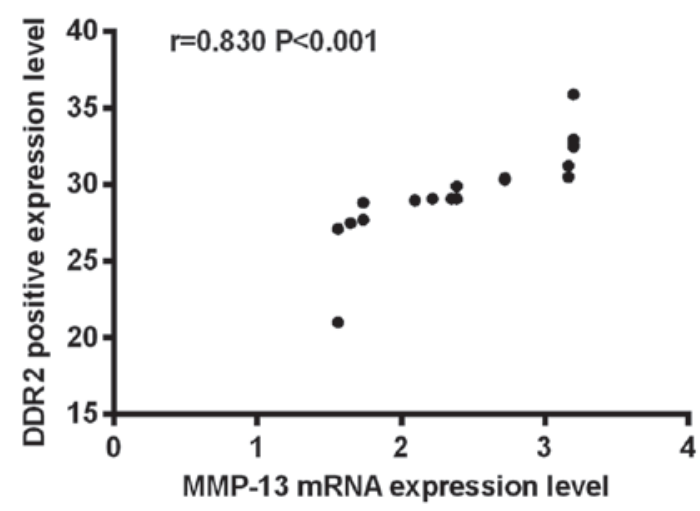

Figure 1. Correlation analysis between MMP-13 mRNA and DDR2 in KOA rats. There was a positive correlation between MMP-13 mRNA and DDR2 in KOA rats $(\mathrm{r}=0.830, \mathrm{P}<0.001)$. MMP-13, matrix metalloproteinase 13; DDR2, discoid domain receptor 2; KOA, knee osteoarthritis.

significant $(\mathrm{P}<0.05)$. Although the positive expression level of DDR2 in the transplantation group after treatment was still higher than that of the blank group, there was no significant difference $(\mathrm{P}>0.05)$ (Table V).

Correlation analysis between MMP-13 $m R N A$ and DDR2 in KOA rats. According to Pearson's correlation analysis, there was a positive correlation between MMP-13 mRNA and DDR 2 in KOA rats $(r=0.830, P<0.001)$, as shown in Fig. 1.

\section{Discussion}

As a chronic degenerative bone and joint disease, in recent years, with the aging of the population, the incidence of KOA is increasing, and the incidence of KOA in the elderly aged over
65 years is even as high as $50 \%$ or more, causing a heavy burden to the family $(16,17)$. At present, treatments for KOA such as hormones and oral COX inhibitors are effective, but their therapeutic effects are still limited (18). For patients who are ineffective in drug therapy, surgery can be performed, although total knee arthroplasty has a good effect on improving patients' pain (19), nearly half of the patients still have long-term pain after surgery, and some patients need to undergo a second operation $(20,21)$. Therefore, seeking a new treatment method for $\mathrm{KOA}$ is an urgent problem to be solved. Adipose-derived stem cells (MSCs) are stem cells with animal models that have strong differentiation ability in nerve regeneration and cartilage regeneration, and have broad application prospects (22). However, there are few studies on the transplantation of ADMSCs for KOA. Therefore, we investigated the effects of ADMSC transplantation on KOA rats and the effects of MMP-13 and DDR2.

After establishing the model, rats were divided into groups and transplanted with ADMSCs. The results showed that the indexes of Lequesne MG knee joints in the transplantation group were lower than those in the KOA group, and the difference was statistically significant $(\mathrm{P}<0.05)$, which indicates that ADMSCs transplantation therapy has a significant effect on improving knee joint score in rats. Some studies (23) have prospectively investigated the efficacy of ADMSCs, and have shown that patients' mobility is significant before and after treatment with ADMSCs. The improvement is consistent with our conclusions, but the experiments herein may have some deviations due to the set of single experiments, so supplemental comparisons should be continued in subsequent experiments. Then, we investigated the expression levels of MMP-13 mRNA and DDR2 before and after treatment in the three groups of rats. The results showed that the expression levels of MMP-13 mRNA and DDR2 in the transplanted and KOA rats before 
treatment were significantly higher than those in the blank group $(\mathrm{P}<0.05)$, indicating that both MMP-13 mRNA and DDR2 were highly expressed in KOA rats.

MMP-13 is an MMP that can effectively degrade various collagens. Studies have reported (24) that MMP-13 is highly expressed in OA patients, and MMP-13 has a certain damage to articular cartilage. Furthermore, it has been shown that DDR2 can increase the expression of MMP-13 in cells, which suggests that when DDR2 is activated, cells can secrete MMP-13 excessively, thereby further destroying cartilage (25). After treatment, the expression of MMP-13 mRNA and DDR2 in the transplanted rats was significantly lower than that in the KOA group $(\mathrm{P}<0.05)$. This result indicated that MMP-13 mRNA and DDR2 expression levels in KOA rats can be effectively improved after treatment with ADMSCs. It was reported that when MMP-13 levels are elevated, the outer structure of chondrocytes may be damaged by degrading the extracellular matrix of the cartilage, thereby triggering KOA (26). Only part of the research on DDR2 (27) showed that it has an important relationship with the formation of osteoblasts and chondrocytes, but there is no relevant research on the expression of MMP-13 and DDR2 in KOA rats treated with ADMSCs transplantation.

In summary, the transplantation of ADMSCs has a significant effect on KOA rats, which can effectively improve the knee joint evaluation of KOA rats as well as the expression of MMP-13 mRNA and DDR2 in rats, and promote the recovery of rats, which is worthy of clinical promotion. However, more in-depth experiments are still required.

\section{Acknowledgements}

Not applicable.

\section{Funding}

This study was supported by the Scientific Research Project of Shanghai Science and Technology Committee (17411968400).

\section{Availability of data and materials}

The datasets used and/or analyzed during the present study are available from the corresponding author on reasonable request.

\section{Authors' contributions}

JL drafted the manuscript. JL and XZ contributed to the isolation and culture of adipose stem cells. QS and FX were responsible for the rat KOA model construction. JL and GS performed PCR. All authors read and approved the final manuscript.

\section{Ethics approval and consent to participate}

The study was approved by the Experimental Animal Ethics Committee of Shanghai East Hospital Tongji University (Shanghai, China).

\section{Patient consent for publication}

Not applicable.

\section{Competing interests}

The authors declare that they have no competing interests.

\section{References}

1. Levinger I, Levinger P, Trenerry MK, Feller JA, Bartlett JR, Bergman N, McKenna MJ and Cameron-Smith D: Increased inflammatory cytokine expression in the vastus lateralis of patients with knee osteoarthritis. Arthritis Rheum 63: 1343-1348, 2011.

2. Cheng J, Hu X, Dai L, Zhang X, Ren B, Shi W, Liu Z, Duan X, Zhang $\mathrm{J}, \mathrm{Fu} \mathrm{X}$, et al: Inhibition of transforming growth factor $\beta$-activated kinase 1 prevents inflammation-related cartilage degradation in osteoarthritis. Sci Rep 6: 34497, 2016.

3. Lotz M, Hashimoto S and Kühn K: Mechanisms of chondrocyte apoptosis. Osteoarthritis Cartilage 7: 389-391, 1999.

4. Yuan GH, Masuko-Hongo K, Kato T and Nishioka K: Immunologic intervention in the pathogenesis of osteoarthritis. Arthritis Rheum 48: 602-611, 2003.

5. Xu M, Zhang L, Zhao L, Gao S, Han R, Su D and Lei G: Phosphorylation of osteopontin in osteoarthritis degenerative cartilage and its effect on matrix metalloprotease 13. Rheumatol Int 33: 1313-1319, 2013.

6. von Mässenhausen A, Sanders C, Brägelmann J, Konantz M, Queisser A, Vogel W, Kristiansen G, Duensing S, Schröck A, Bootz F, et al: Targeting DDR2 in head and neck squamous cell carcinoma with dasatinib. Int J Cancer 139: 2359-2369, 2016.

7. Klatt AR, Zech D, Kühn G, Paul-Klausch B, Klinger G, Renno JH, Schmidt J, Malchau G and Wielckens K: Discoidin domain receptor 2 mediates the collagen II-dependent release of interleukin- 6 in primary human chondrocytes. J Pathol 218: 241-247, 2009.

8. Zhang W, Ding T, Zhang J, Su J, Li F, Liu X, Ma W and Yao L: Expression of discoidin domain receptor 2 (DDR2) extracellular domain in pichia pastoris and functional analysis in synovial fibroblasts and NIT3T3 cells. Mol Cell Biochem 290: 43-53, 2006.

9. Choi K, Kang BJ, Kim H, Lee S, Bae S, Kweon OK and Kim WH: Low-level laser therapy promotes the osteogenic potential of adipose-derived mesenchymal stem cells seeded on an acellular dermal matrix. J Biomed Mater Res B Appl Biomater 101: 919-928, 2013.

10. Rhee SC, Ji YH, Gharibjanian NA, Dhong ES, Park SH and Yoon ES: In vivo evaluation of mixtures of uncultured freshly isolated adipose-derived stem cells and demineralized bone matrix for bone regeneration in a rat critically sized calvarial defect model. Stem Cells Dev 20: 233-242, 2011.

11. Han DS, Chang HK, Kim KR and Woo SM: Consideration of bone regeneration effect of stem cells: Comparison of bone regeneration between bone marrow stem cells and adiposederived stem cells. J Craniofac Surg 25: 196-201, 2014.

12. de Souza RA, Xavier M, Mangueira NM, Santos AP, Pinheiro AL, Villaverde AB and Silveira L Jr: Raman spectroscopy detection of molecular changes associated with two experimental models of osteoarthritis in rats. Lasers Med Sci 29: 797-804, 2014.

13. Seo BK, Park DS and Baek YH: The analgesic effect of electroacupuncture on inflammatory pain in the rat model of collagenase-induced arthritis: Mediation by opioidergic receptors. Rheumatol Int 33: 1177-1183, 2013.

14. Mohelnikova-Duchonova B, Oliverius M, Honsova E and Soucek P: Evaluation of reference genes and normalization strategy for quantitative real-time PCR in human pancreatic carcinoma. Dis Markers 32: 203-210, 2012.

15. Lequesne MG and Maheu E: Methodology of clinical trials in hand osteoarthritis: conventional and proposed tools. Osteoarthritis Cartilage 8 (Suppl A): S64-S69, 2000.

16. Felson DT, Naimark A, Anderson J, Kazis L, Castelli W and Meenan RF: The prevalence of knee osteoarthritis in the elderly. The Framingham Osteoarthritis Study. Arthritis Rheum 30: 914-918, 1987.

17. Cross M, Smith E, Hoy D, Nolte S, Ackerman I, Fransen M, Bridgett L, Williams S, Guillemin F, Hill CL, et al: The global burden of hip and knee osteoarthritis: Estimates from the global burden of disease 2010 study. Ann Rheum Dis 73: 1323-1330, 2014.

18. McAlindon TE, Bannuru RR, Sullivan MC, Arden NK, Berenbaum F, Bierma-Zeinstra SM, Hawker GA, Henrotin Y, Hunter DJ, Kawaguchi H, et al: OARSI guidelines for the non-surgical management of knee osteoarthritis. Osteoarthritis Cartilage 22: 363-388, 2014. 
19. Jevsevar DS: Treatment of osteoarthritis of the knee: Evidencebased guideline, 2nd edition. J Am Acad Orthop Surg 21: 571-576, 2013.

20. Wylde V, Hewlett S, Learmonth ID and Dieppe P: Persistent pain after joint replacement: Prevalence, sensory qualities, and postoperative determinants. Pain 152: 566-572, 2011.

21. Bayliss LE, Culliford D, Monk AP, Glyn-Jones S, PrietoAlhambra D, Judge A, Cooper C, Carr AJ, Arden NK, Beard DJ, et al: The effect of patient age at intervention on risk of implant revision after total replacement of the hip or knee: A populationbased cohort study. Lancet 389: 1424-1430, 2017.

22. Naderi N, Combellack EJ, Griffin M, Sedaghati T, Javed M, Findlay MW, Wallace CG, Mosahebi A, Butler PE, Seifalian AM, et al: The regenerative role of adipose-derived stem cells (ADSC) in plastic and reconstructive surgery. Int Wound J 14: 112-124, 2017.

23. Bansal H, Comella K, Leon J, Verma P, Agrawal D, Koka P and Ichim T: Intra-articular injection in the knee of adipose derived stromal cells (stromal vascular fraction) and platelet rich plasma for osteoarthritis. J Transl Med 15: 141, 2017.

24. Inada M, Wang Y, Byrne MH, Rahman MU, Miyaura C, López-Otín C and Krane SM: Critical roles for collagenase-3 (Mmp13) in development of growth plate cartilage and in endochondral ossification. Proc Natl Acad Sci USA 101: 17192-17197, 2004.
25. Xu L, Peng H, Wu D, Hu K, Goldring MB, Olsen BR and Li Y: Activation of the discoidin domain receptor 2 induces expression of matrix metalloproteinase 13 associated with osteoarthritis in mice. J Biol Chem 280: 548-555, 2005.

26. Vincenti MP and Brinckerhoff CE: Transcriptional regulation of collagenase (MMP-1, MMP-13) genes in arthritis: Integration of complex signaling pathways for the recruitment of gene-specific transcription factors. Arthritis Res 4: 157-164, 2002.

27. Zhang Y, Su J, Yu J, Bu X, Ren T, Liu X and Yao L: An essential role of discoidin domain receptor 2 (DDR2) in osteoblast differentiation and chondrocyte maturation via modulation of Runx2 activation. J Bone Miner Res 26: 604-617, 2011.

This work is licensed under a Creative Commons

Attribution-NonCommercial-NoDerivatives 4.0 International (CC BY-NC-ND 4.0) License. 